\title{
Bridging the gap between patient needs and quality indicators: a qualitative study with chronic heart failure patients
}

This article was published in the following Dove Press journal:

Patient Preference and Adherence

30 September 2015

Number of times this article has been viewed

\author{
Ines Baudendistel' \\ Stefan Noest ${ }^{\prime}$ \\ Frank Peters-Klimm' \\ Heidrun Herzberg ${ }^{2}$ \\ Martin Scherer ${ }^{3}$ \\ Eva Blozik ${ }^{3}$ \\ Stefanie Joos ${ }^{1,4}$
}

'Department of General Practice and Health Services Research, University Hospital Heidelberg, Heidelberg, Germany; ${ }^{2}$ Faculty of Health, Nursing, Administration, University of Applied Sciences Neubrandenburg, Neubrandenburg, Germany; ${ }^{3}$ Department of Primary Medical Care, University Medical Center HamburgEppendorf, Hamburg, Germany; ${ }^{4}$ Institute for General Practice and Interprofessional Care, University Hospital Tuebingen, Tuebingen, Germany
Correspondence: Stefanie Joos Institute for General Practice and Interprofessional Care, University Hospital Tuebingen, Oesterbergstraße 9, 72074 Tuebingen, Germany

Tel +49 707I 2985226

Fax+49 707I 295896

Email stefanie.joos@med.uni-tuebingen. de
Background: The German National Disease Management Guideline (NDMG) on chronic heart failure (CHF) derived nine clinical quality indicators (QIs) to enable assessment of quality of health care in patients with CHF. These QIs epitomize an evidence-based and somatic point of view of guided treatment, but little is known about the experiences and views of patients with their guideline-based treatment across multiple health care sectors.

Objective: The purpose of this qualitative study was to explore patient perspectives on guided treatment of CHF across multiple health care sectors. Furthermore, it was investigated to what extent patient perspectives are represented by the QIs of the German NDMG.

Methods: Using a qualitative approach, semistructured interviews were carried out with 17 CHF patients. Interviews were audio-recorded and transcribed verbatim. Data were analyzed using qualitative content analysis.

Results: Patient-identified needs focused primarily on aspects like the doctor-patient relationship, communication, quality of individual-tailored information, and professional advice. Patients perceived shortcomings in processes of care such as communication and cooperation across health care sectors, especially at the transition between hospital and outpatient care.

Discussion: From the patient perspectives, the QIs do represent relevant somatic and clinical aims for quality measurement. However, deficits were identified, especially related to communication and cooperation across health care sectors. Given the fact that the inclusion of patient perspectives in quality improvement processes provides an important contribution to patient-centered health care, possible approaches for QI development such as direct and indirect patient involvement or generic vs disease-specific patient-related QIs should be the subject of future discussions.

Keywords: quality indicators, patient involvement, patient perspectives, chronic heart failure, national disease management guideline

\section{Background}

Patients with chronic heart failure (CHF) strongly suffer from their illness, which is characterized by a high physical and psychological burden of symptoms (eg, dyspnea, fatigue, ankle swelling, and depression), a high mortality, and a high (often unplanned) utilization of the health care system..$^{1,2}$ A considerable number of studies show that the quality of life in patients with CHF is often strongly limited by psychosocial aspects. ${ }^{3-7}$ The therapy of patients with CHF is often complex and requires a close cooperation across health care sectors. At the same time, patients are often inadequately involved in therapy decision-making processes ${ }^{8}$ Considering the complexity of the illness, a high level of patient participation in the treatment process is required. Yet, little is known about patient experiences and views on treatment and thus what they perceive as important in the context of quality of care. 
The US-American Institute of Medicine has identified "patient centeredness" as a main objective for quality improvement. In this context, patient-centered care is defined as care "which shows respect and responsibility to preferences, needs and values of patients". ${ }^{9}$ Clinical practice guidelines and quality indicators (QIs) are central elements in striving for a high quality of health care. There is international consensus about the fact that QIs have to be relevant to patients. This is even more important in complex chronic conditions where a high adherence to treatment is inevitable. However, there is no existing common methodological gold standard for patient involvement in developing QIs as yet. ${ }^{10}$ First experiences exist in different fields of medicine, eg, cancer care and fertility disorders. ${ }^{10-13}$ Also in Germany, this issue raised attention, eg, patient representatives are involved in developing processes of the German National Disease Management Guidelines (NDMG). ${ }^{14}$ The German NDMG on CHF (published in 2009) was created in a standardized development process with participation of 15 experts from eleven different professional associations and one patient representative. ${ }^{15,16}$ In a formalized process, nine ratio-based process indicators were derived from evidencebased recommendations to enable assessment of quality of health care in patients with $\mathrm{CHF} .^{17}$

The purpose of this qualitative study was to explore the perspectives of patients with CHF on their treatment across multiple health care sectors and to investigate to what extent patient perspectives are represented by the QIs from the German NDMG on CHF.

\section{Methods}

This qualitative study is part of the QUALIPAT heart project (QUALity Indicators in health care: a qualitative analysis of PATient involvement using the example of heart failure), funded by the German Federal Ministry of Education and Research. ${ }^{18}$ The QUALIPAT heart project consists of three subprojects: 1) exploring individual patient views, 2) exploring patient groups, and 3 ) exploring perspectives of doctors, experts, and stakeholders. In all three subprojects, a qualitative study design was used to enable an intensive exploration of the perspectives. This manuscript describes the results of the first subproject (exploring individual patient views).

\section{Recruitment}

Patients were recruited via general practitioner (GP) practices from a network of 85 academic research practices of the Medical Faculty of the Department of General Practice and Health Services Research at University Hospital Heidelberg. ${ }^{19}$
GPs were contacted by telephone and additionally invited in written form to support the patient recruitment. Six GP practices agreed to participate and received a list of selection criteria for the recruitment of suitable patients. The selection criteria comprised the presence of a chronic systolic heart failure (ejection fraction $<35 \%$ ), age $>18$ years, and sufficient knowledge of the German language. Eligible patients were contacted and appointments for conducting the interview were arranged.

\section{Data collection}

The interviews were conducted by the lead author (IB) from October 2012 to December 2012 in the participants' domestic environment $(n=16)$, and at the Department of General Practice and Health Services Research, University Hospital Heidelberg $(n=1)$. The interviews took 30-83 minutes, except one interview with a patient whose health condition deteriorated acutely. This interview was interrupted after 4 minutes, in order to relieve the participant. The study objectives were made transparent to the participants. In order to avoid unclear questions or misunderstandings, it was made sure that all aspects of the questions were explained before the interview. The interviews were digitally recorded and transcribed verbatim.

\section{Interview guideline}

The interview guideline was developed by an interprofessional team of researchers (nursing and health scientist [IB], sociologist with a nursing background [SN], and two practicing GPs with experience in qualitative research [SJ, FPK]). The pilot-tested interview guideline started with general questions on health care quality from the patient perspective, referring to the patient experiences and expectations. The second part focused on specific topics along the process of care, referring to the nine QIs (classified in six QI domains) taken from the German NDMG on CHF (Figure 1).

\section{Ethics}

The study was approved by the ethics commission of the Medical Faculty Heidelberg (23.07.2012, S-233/2012). All participants gave their written consent prior to the start of the interviews.

\section{Data analysis}

Data analysis was carried out using the ATLAS.ti software (version 7.0.80) (ATLAS.ti scientific software development $\mathrm{GmbH}$, Berlin, Germany). On the basis of the content analysis according to Mayring, ${ }^{20}$ key issues were identified, 


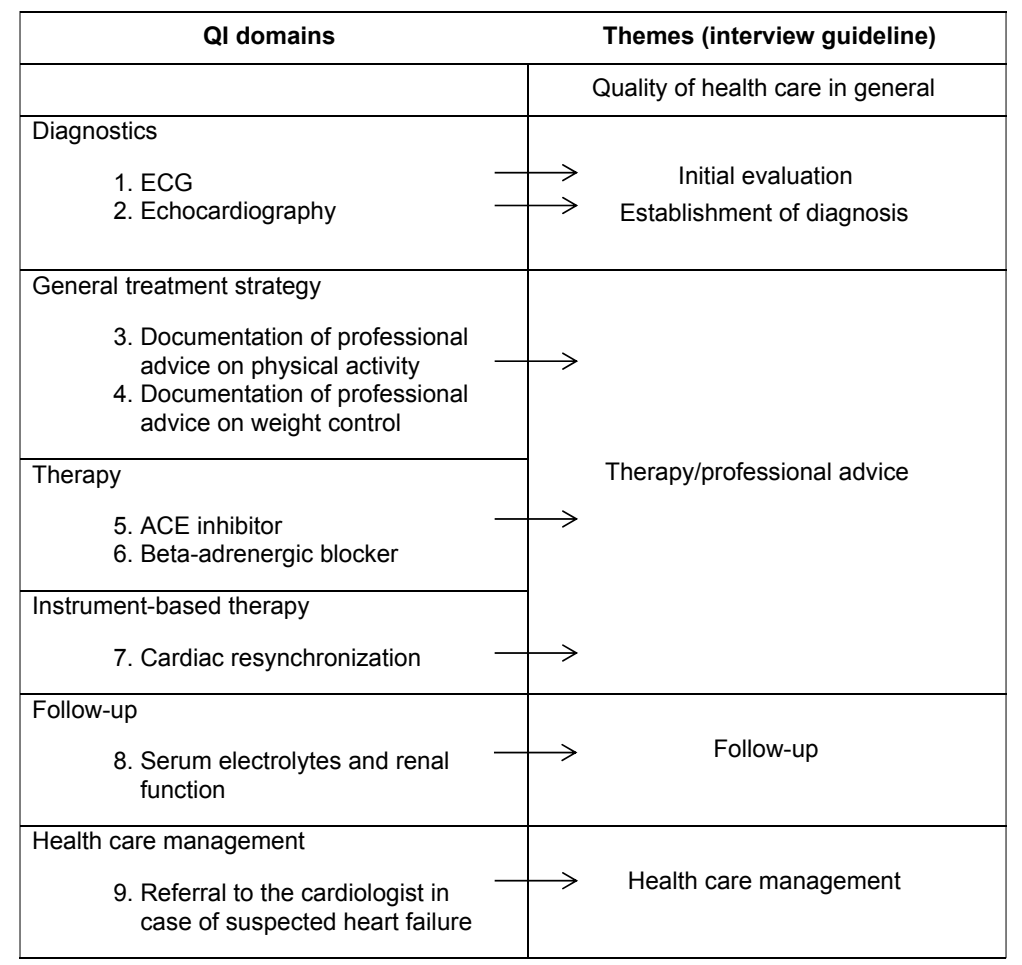

Figure I Summary of the domains of the QI from the German National Disease Management Guideline for chronic heart failure and the interview guidelines' themes. Abbreviations: QI, quality indicators; ECG, electrocardiogram; ACE, angiotensin converting enzyme.

summarized, and labeled as codes and sorted into categories. Qualitative content analysis implies an inductive development of categories and a deductive application of categories. ${ }^{20}$ According to the rules of the qualitative content analysis, the categories were developed near to the original material. The category's description was made by attributing every category to a representative quotation. ${ }^{21}$ Two researchers (IB and SN) reviewed the transcripts independently. The categorizing system was consequently modified, and disagreements throughout the process were discussed within the research team until a consensus was achieved. The categorizing system with its head topics and main categories was initially developed in German language and afterward translated into English by IB and cross-checked by all coauthors. The quotations cited in this article were translated by IB and cross-checked by FPK.

\section{Results}

Overall, 5 women and 12 men participated in the interviews (Table 1). The participants were on average 71.5 (SD 11.6) years old and had 4.4 (SD 1.8) additional chronic conditions. About 13 of the 17 participants took more than seven medications per day.

In the following sections, the results of this qualitative analysis are presented. Table 2 gives an overview of the head topics of the category systems and its main categories which are described and linked with representative quotations in the text.

\section{Quality of health care in general}

In general, the interviewees were satisfied with the quality of their health care. However, their satisfaction was dependent on the health care sector. Especially for primary care, patients described a high satisfaction.

Table I Patient characteristics $(n=17)$

\begin{tabular}{ll}
\hline Sex & \\
Female $(\mathrm{n})$ & 5 \\
Male (n) & 12 \\
Age (in years) & $71.5($ II.6) \\
$\quad$ Mean (SD) & $5 \mathrm{I}-87$ \\
Range & \\
Employment & 14 \\
$\quad$ Retiree & 1 \\
Housewife & 2 \\
Others & \\
Number of additional chronic conditions & $4.4(1.8)$ \\
$\quad$ Mean (SD) & \\
Number of taken drugs (self-reported) & 13 \\
$>7$ drugs & 4 \\
$<7$ drugs
\end{tabular}

Abbreviation: SD, standard deviation. 
Table 2 Category system on patient-relevant aspects of quality of health care

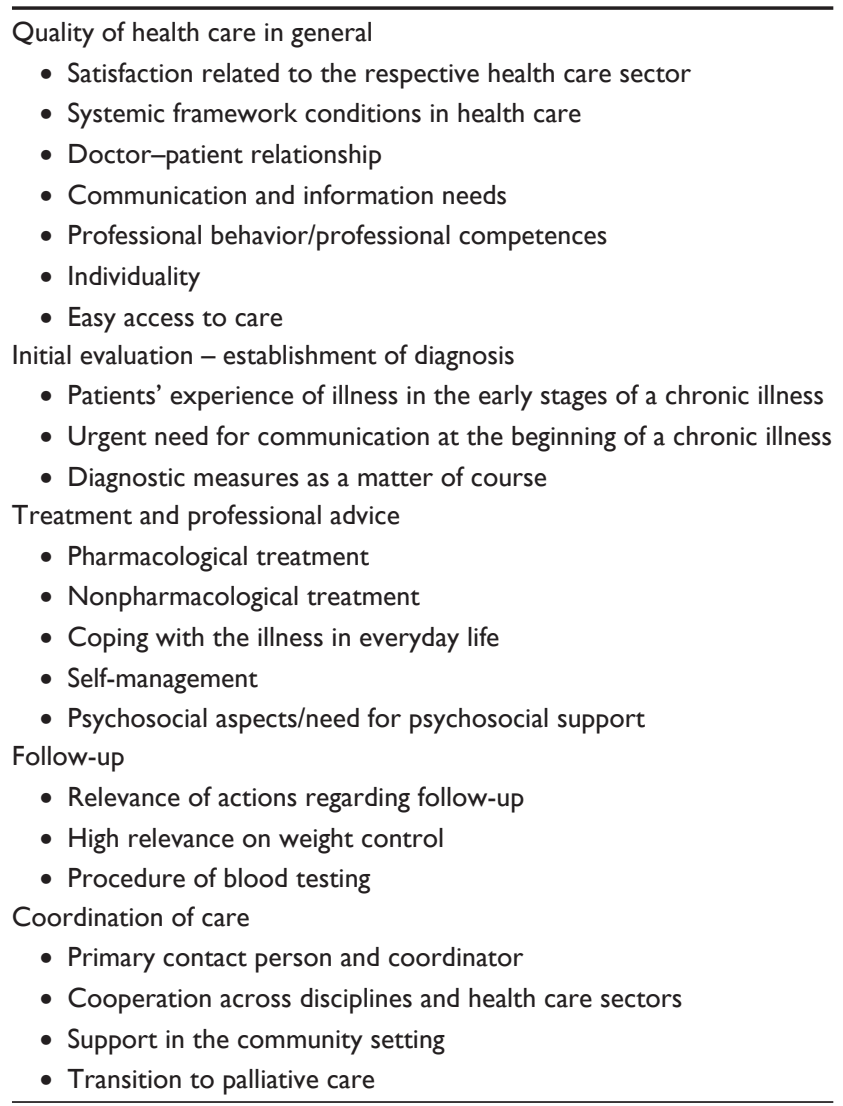

I have no reason to complain anyhow. Well, my GP provides, let's say, very good medical care. [P5]

In contrast, patient experiences within the inpatient sector (hospitals, rehabilitation clinic) were more heterogeneous. Patients reported negative experiences relating to time and availability of physicians.

Respective the hospital, my experiences are quite mixed.

[...] You have to worship the doctors. Otherwise you got no chance to get to know anything [...]. There is therefore quite a big deficit. Here, I wish that it gets a little bit better. [P1]

Many interviewees proposed time and cost pressure as reasons for their negative experiences.

Another key aspect was a good doctor-patient relationship. Mostly, patients associated it with a long-term relationship, characterized by openness, trust, and appreciation. In this context, often the relationship with their GP was mentioned.

...the GP is my doctor, and I know him for my whole life and I can talk to him like talking with you now too and I have no reluctance. [P14]
In general, communication was a central topic throughout the interviews. The conversation with the doctor was regarded as an indicator for good care.

A simple conversation with the doctor ... So, everything is explained to me, what it is all about and what is going on. [P2]

Some patients addressed their unfulfilled needs for information - in terms of quality and quantity of information.

More information. [P8]

... that they talk in a better way to me. [P17]

Many of the participants stressed the role of professional competence. This also includes being appreciated in their individuality. Specifically, they wished that health care be adapted to their individual situation and that the individual patient's needs are considered in all health care sectors.

...In these days, when I come to see a cardiologist, he is doing his job. I come with an assignment. Either he is controlling my pacemaker, because I have a pacemaker, or he is checking my... well it is more or less technology-based medicine. But asking him something personal, you hardly won't get an answer. You can [only] ask about what the technical device is telling ... [P16]

For the interviewees, an easy access to care by means of having a contact partner, eg, a GP or a health care assistant, and getting timely appointments were further indicators for a good quality of health care, whereas long waiting times were criticized, particularly in situations described as critical by patients, eg, having acute health problems.

\section{Initial evaluation - establishment of diagnosis}

This head topic is characterized by the patient experience of illness in the early stages of the chronic illness. Some interviewees described their illness as a "creeping process". In most patients, limiting symptoms or an acute event appeared at the beginning. Receiving the diagnosis of $\mathrm{CHF}$ was often perceived as a shock accompanied by anxiety and uncertainty.

This made me feel sick, uncomfortable. If you see what ... Is this your last hour? You never know. If your hear some people telling, who have problems with their heart too, what it is, how, what ... [P11] 
Some interviewees expressed an urgent need for communication with health professionals and for information about their health situation at that point of time.

The senior resident Dr... he shortly explained the issue and then he did some other measures, which apparently were associated with or brought results, but nothing else. My principal point of contact was my GP. And he took his time. I had my appointment at 7 o'clock, although the doctor's office started at 8 o'clock first, so that he had enough time for me. [P5]

According to diagnostic measures, it became apparent that patients perceived these a matter of course. Recording of electrocardiogram or echocardiographies were taken for granted, and their relevance to the treatment was accepted and unquestioned.

\section{Treatment and professional advice}

Pharmacological treatment was relevant to the interviewees, especially the quality of professional counseling was central (the "how" and the "how much" related to information on medication). Thereby, comprehensibility of the information provided was considered as important.

Well, let's say, it was cracked superficially, yes. As I said before, then these Latin words came up again. And then it has been called, read the patient information leaflet too, and if something goes wrong, you come back immediately. [P5]

As a positive example for a "good" counseling, one interviewee mentioned the training in a rehabilitation center, where he received explanations of indications and the active principle of drugs.

...During rehabilitation, after receiving my bypass, this was very good too. We had a trainer, who was really good [...] And he truly explained to us, what the single things are doing and why it is important to take them, and so on.

[P1]

Furthermore, the nonpharmacological treatment was often addressed. Issues about physical exercise and lifestyle change, eg, reducing burdens, smoking cessation, or changing nutrition habits, were mentioned in this context. Thereby, the perception of physical limitations related with coping with everyday life with the illness was central. At this point, issues of CHF self-care and self-management arose.

It is up to me to handle weight, my health, which limitations

I do have. That I take care of my physical exercise, that I do not exhaust myself. [P8] ...but I was a cook and in that business it is hectical. So, you can't say, well, now we do relax and go on slower. Well, for me it was a challenge on acting more relaxed and doing less. In the past I did very much walking with my wife for hours ... this is missing now completely. And I was an active swimmer, until I had my heart attack. [P5]

According to some patients, themes like physical exercise and, especially, the provision of exercise training as a health service to patients did not get enough attention by doctors.

From the doctors side, no, nothing, nothing at all. As I told you before, the knowledge (on physical activity) I got from the rehabilitation. There, they addressed those things, they gave courses, in that way you get to know these things. But from the doctor's side - nothing. Well, my GP said to me: "do some cardiac exercise and so on". But as I told you before, I got no free place in a cardiac exercise group until today. [P1]

Participants recurrently raised psychosocial aspects such as burden through anxiety or depressed mood or through care giving for a spouse or the loss of a spouse.

Well, especially to me, this is, I have got a certain anxiety disorder. Sometimes I do suffer from panic attacks. [P1]

The need for psychosocial support, eg, in coping with illness experiences, was addressed by several interviewees.

\section{Follow-up}

In general, actions on follow-up were relevant to the interviewees because they give orientation and security.

Well, for me yes [...] Well, it is giving a certain kind of orientation to you, a plan where you know if things run fairly straight or if you to let things slide. [P12]

It gives a certain feeling security to you, well yes. [P1]

As a follow-up process from the patient's view, weight control was an often addressed issue. Most of the interviewees described actions in self-management, eg, in case of rapid weight increase. Self-management and self-examination were mentioned, whereas realizing the relevance of routine weight controls conducted by the patients themselves was crucial.

Well, I have got a ... over there, Mrs.... the doctor, [...], she explained to me that if my weight is one kilo more, I have to contact them immediately. If it is two kilo in ... so and so many hours, I have to contact them. But it was not the fact, 
because my weight is stable. No, they are, well honestly,

they are very concerned about me ... [P14]

The procedure of blood testing was described clearly by most of the interviewees. However, the indication and consequences for doing so were addressed less often and was unclear to most of the interviewees.

\section{Coordination of care}

The presence of a primary contact person was an important point to the interviewees. Mostly, the GP was described as the primary contact person. He often was perceived as a coordinator.

However, some interviewees named their resident cardiologist as their primary contact person.

Well, for me my GP is a central person. Well, a central point is a part of... I'm always telling, if I had another illness, where I do need a specialist, the GP is still, at least for me, he is still the key person. [P16]

The cardiologist ... because he is the cardiac specialist. [P6]

Cooperation between the medical disciplines and across health care sectors was a key topic for most of the interviewees. From the patients' perspective, a closer cooperation is needed. Deficits in information exchange and communication, especially on behalf of the inpatient sector, were expressed by the interviewees.

....No, the hospital certainly not ... a direct communication with the doctor or the cardiologist (in ambulatory care) almost does not take place. Between my GP and my cardiologist, yes. If it is something serious, mostly he is referring me directly to hospital. But in my opinion the communication between hospital and other doctors is awfully bad. [P1]

Joint discussions of medical findings or fast information exchanges between, eg, GPs and cardiologists were mentioned to be positive. Organizational aspects according to acute hospital admissions, transitions from hospital to the rehabilitation setting, or from hospital to home were discussed. Clear responsibilities and organizational processes, eg, in case of application for a rehabilitation were relevant to the interviewees.

I tell you frankly, I could have been much more better with my health status... where I could have started three weeks earlier with therapies [...] I had to learn everything concerning writing, talking and walking autonomously on my own at home. Always just step by step, every day a little bit more. Basically, this is this time that is missing

to me. [P12]

The need for support in the community setting to cope with challenges in everyday life was a further important point, eg, support in housekeeping, sustaining autonomy at home as long as possible, and support in participation in cardiac exercise groups as well as self-help groups.

The worst of all to me was the fact, that you can't help yourself after receiving your bypass. I did not obtain an extension of my stay in the rehabilitation clinic. To say it in plain language, they threw me out after three weeks and I could not move, I could not move a muscle. I suffered very much from pain. Well, then they said: "Go home, keep your house and so on". But it doesn't work like that, you are not able to do so, then you are on your own, nobody helps you, nobody! [P1]

Care in the advanced phase of chronic illness, respectively palliative care, was mentioned by some interviewees, especially in elderly. Issues like increasing dependency on care and the need to be under care at home were addressed.

...Well, my daughter identified the issue and organized short-term nursing care [in a nursing home] for me. But I can't expect it every time ... Now, it is the third time that somebody came to my home (assessing the level nursing care dependency). Now, I'm curious if it (application for nursing care dependency) is rejected again. [P9]

\section{Discussion}

This qualitative study identified patient-relevant aspects on quality of health care in guided treatment of patients with CHF by exploring patient experiences and views. Our results show that the interviewed patients were mostly satisfied with their health care. Patient experiences within the inpatient sector were often reported to be less positive, whereas most patients had good experiences with the GPs' treatment in primary care. Patient needs focused primarily on doctorpatient relationship, communication, quality of information, and professional advice, as well as psychosocial support. However, patients also expressed relevant deficits regarding their health care. Particularly, patients reported shortcomings related to cooperation between health care professionals within the whole range of treatment across multiple health care sectors. Furthermore, they described structural deficits with regard to area-wide available services (eg, patient education, counseling, and programs on physical exercise). 
These aspects are not measured by the current set of QIs taken from evidence-based recommendations of the German NDMG on CHF. The current nine clinical QIs do represent relevant clinical aspects of guided treatment (eg, diagnostics with ECG or echocardiography, pharmacological therapy). However, they do not sufficiently represent the dimensions of high quality of care that is relevant to patients as our results show. The fact that the interviewees did not discuss very much about technical measures (eg, echocardiography) is understandable because patients are (mostly) medical laypersons. However, patients may be regarded as experts in living with a chronic illness ${ }^{22}$ characterized by everyday life orientation. They perceived diagnostic measures as relevant, but did not address them as much as the aspects regarding communication and cooperation. Gallacher et $\mathrm{a}^{23}$ concluded in a systematic review that frequent consultations with the doctor are to be coordinated and that the missing continuity of health care and shortages in communication among doctors are relevant negative factors for CHF patients.

In agreement with previous studies, our results show that CHF patients perceive their diagnosis and therapy as very complex. Besides physical problems, they especially suffer from psychosocial burdens related to their illness. ${ }^{5,24}$ The results of our findings did not vary extensively from those of people living with heart failure in other countries, eg, in Asia, and it seems that patient perspectives on information needs or involvement in medication regimes are transcultural on a meta-level of patient experiences and needs. ${ }^{25,26}$ However, based on transcultural differences in strategies of coping, patient needs are slightly different; while for Asian patients, spiritual and family systems seem to be important resources of coping, ${ }^{25}$ patients in our sample often express their need for professional help, eg, psychosocial support.

\section{Integrate patient views}

Given the identified gap between the existing QIs and the patient-identified needs, it has to be discussed whether the current QI-development process is suitable for involving patient perspectives. Although most of the aspects identified in our study are addressed in the German NDMG on CHF, they are not supposed to be part of a candidate set of QI because strong evidence for those treatment recommendations does not exist. The formalized procedure for developing ratio-based QIs, as it is the current state-of-the-art internationally, may be an explanation for it. ${ }^{27,28}$

Further, developing independent patient indicators that supplement professional perspectives on quality of care could be an approach to fill the current gap for CHF. A crucial prerequisite to integrate patient views in guideline and QI development is to create further external evidence for patient perspectives on quality of health care. Furthermore, suitable methods to identify patient perspectives, especially in case of treatment across several health care sectors, are qualitative methods such as personal interviews or focus groups with patients. ${ }^{29,30}$

Several first approaches of patient involvement in QI development are available. Thus, having a look in other fields in medicine such as cancer care and in the field of fertility disorders could be helpful. ${ }^{10-13}$ The methods used range from indirect patient involvement through questionnaire surveys about patient experiences as well as interviews and focus groups as mentioned above to direct involvement, eg, expert panels in the course of QI-development processes. ${ }^{10,31-33} \mathrm{The}$ currently published study of den Breejen et $\mathrm{al}^{11}$ describes a possible way of direct patient involvement for patient centeredness in fertility disorders. The authors presented a set of QIs from 119 indicators to an expert panel and to a patient panel. The expert panel selected 16 indicators, the patient panel selected 18 indicators with five overlapping indicators. Practical implementation of the QIs will be investigated in the next step. ${ }^{11}$

A challenge, which is relevant to all methods of patient involvement mentioned before, is the recruitment of patients to be involved. Those patients should have a good knowledge about their illness, but still be connectable to the "everyday knowledge" of the majority of patients with CHF. ${ }^{34}$ This challenge is also seen by the experts in the other subproject of the QUALIPAT heart study. ${ }^{35}$

\section{Strengths and limitations of the study}

The strength of this study was that it was conducted by an interprofessional team of researchers with different backgrounds. After performing 17 interviews, no new aspects emerged, so a saturation of theoretical arguments can be assumed. Because of recruitment via GPs, a selection in patients as well as a possible influence of the answers in sense of a social desirability cannot be excluded.

\section{Conclusion}

From the patient perspectives, the nine clinical QIs derived from evidence-based driven process of the German NDMG recommendations do represent well the somatic and clinical aims to measure quality. However, deficits were identified, especially relating to communication and cooperation across health care sectors. Including patient perspectives in quality improvement processes may provide an important 
contribution on the way to a high quality of patient-centered health care. Possible approaches for the QI development, such as direct and indirect involvement of patients, should be the subject of future discussions. In terms of additional patient indicators that would supplement clinical indicators, it has to be further discussed whether they should be conceptualized generically or for specific illness.

\section{Acknowledgments}

The authors would like to thank all the interviewees and project partners. This study was funded by the German Federal Ministry of Education and Research (funding code 01GY1123).

\section{Author contributions}

All authors contributed toward data analysis, drafting and revising the paper and agree to be accountable for all aspects of the work.

\section{Disclosure}

The authors report no conflicts of interest in this work.

\section{References}

1. McMurray JJ, Pfeffer MA. Heart failure. Lancet. 2005;365(9474): $1877-1889$.

2. Neumann T, Biermann J, Neumann A, et al. [Heart failure: the commonest reason for hospitalization in Germany - medical and economic perspectives]. Dtsch Arztebl Int. 2009;106(16):269-275. German.

3. Scherer M, Stanske B, Wetzel D, et al. Psychische Kosymptomatik von hausärztlichen Patienten mit Herzinsuffizienz. [Psychosocial determinants for frequent primary health care utilisation in patients with heart failure]. Herz. 2006;31(4):347-354. German.

4. Scherer M, Himmel W, Stanske B, et al. Psychological distress in primary care patients with heart failure: a longitudinal study. Br J Gen Pract. 2007;57(543):801-807.

5. Yu DS, Lee DT, Kwong AN, et al. Living with chronic heart failure: a review of qualitative studies of older people. J Adv Nurs. 2008;61(5): 474-483.

6. Müller-Tasch T, Peters-Klimm F, Schellberg D, et al. Depression is a major determinant of quality of life in patients with chronic systolic heart failure in general practice. J Card Fail. 2007;13(10):818-824.

7. Peters-Klimm F, Kunz CU, Laux G, et al. Patient- and provider-related determinants of generic and specific health-related quality of life of patients with chronic systolic heart failure in primary care: a crosssectional study. Health Qual Life Outcomes. 2010;8:98.

8. Murray SA, Boyd K, Kendall M, et al. Dying of lung cancer or cardiac failure: prospective qualitative interview study of patients and their carers in the community. BMJ. 2002;325(7370):929.

9. Epstein RM, Street RL Jr. The values and value of patient-centered care. Ann Fam Med. 2011;9(2):100-103.

10. Kötter T, Schaefer FA, Scherer M, et al. Involving patients in quality indicator development - a systematic review. Patient Prefer Adherence. 2013;7:259-268.

11. den Breejen EM, Nelen WL, Schol SF, et al. Development of guidelinebased indicators for patient-centredness in fertility care: what patients add. Hum Reprod. 2013;28(4):987-996.
12. Ouwens M, Hermens R, Hulscher M, et al. Development of indicators for patient-centred cancer care. Support Care Cancer. 2010;18(1): $121-130$.

13. Uphoff EP, Wennekes L, Punt CJ, et al. Development of generic quality indicators for patient-centered cancer care by using a RAND modified Delphi method. Cancer Nurs. 2012;35(1):29-37.

14. Matzat J. Self-help meets science: patient participation in guideline development. Z Evid Fortbild Qual Gesundhwes. 2013;107(4-5):314-319.

15. Programm Nationale VersorgungsLeitlinien. Nationale VersorgungsLeitlinie Herzinsuffizienz - Dokumentübersicht. Berlin, Germany: Programm Nationale VersorgungsLeitlinien. Available from: http:// www.versorgungsleitlinien.de/themen/herzinsuffizienz. Accessed October 2014. German.

16. Weinbrenner S, Langer T, Scherer M, et al. [The German national disease management guideline "chronic heart failure"]. Dtsch Med Wochenschr. 2012;137(5):219-227. German.

17. ÄZG. Handbuch Patientenbeteiligung. Beteiligung am Programm Nationale VersorgungsLeitlinien. Neukirchen: Make a book; 2008. German.

18. Datenbank Versorgungsforschung Deutschland. Köln, Germany: Datenbank Versorgungsforschung Deutschland. Available from: http://www. versorgungsforschung-deutschland.de/show.php?pid=786. Accessed October 2014. German.

19. Peters-Klimm F, Freund T, Bentner M, et al. "In the practice and for the practice!" A workshop report of the development of an academic practice-based research net. Z Allg Med. 2013;89(4):183-188.

20. Mayring P. Qualitative Inhaltsanalyse. Grundlagen und Techniken. Weinheim, Germany: Beltz; 2010.

21. Krippendorff K. Content Analysis. An Introduction to Its Methodology. Beverly Hills, CA: Sage; 1980.

22. Paterson BL, Russell C, Thorne S. Critical analysis of everyday self-care decision making in chronic illness. J Adv Nurs. 2001;35(3):335-341.

23. Gallacher K, May CR, Montori VM, et al. Understanding patients' experiences of treatment burden in chronic heart failure using normalization process theory. Ann Fam Med. 2011;9(3):235-243.

24. Jeon YH, Kraus SG, Jowsey T, et al. The experience of living with chronic heart failure: a narrative review of qualitative studies. $B M C$ Health Serv Res. 2010;10:77.

25. Seah ACW, Tan KK, Huang Gan JC, et al. Experiences of patients living with heart failure: a descriptive qualitative study. $J$ Transcult Nurs. Epub February 26, 2015.

26. Ming, LC, Hassali MA, Shafie AA, et al. Perspectives of heart failure patients in Malaysia towards medications and disease state management: findings from a qualitative study. J Public Health. 2011;19(6): 569-577.

27. Kötter T, Blozik E, Scherer M. Methods for the guideline-based development of quality indicators - a systematic review. Implement Sci. 2012;7:21.

28. Blozik E, Nothacker M, Bunk T, et al. Simultaneous development of guidelines and quality indicators - how do guideline groups act? A worldwide survey. Int J Health Care Qual Assur. 2012;25(8):712-729.

29. Ludt S, Heiss F, Glassen K, et al. Patients' perspectives beyond sectoral borders between inpatient and outpatient care - patients' experiences and preferences along cross-sectoral episodes of care. Gesundheitswesen. 2014;76(6):359-365.

30. Noest S, Ludt S, Klingenberg A, et al. Involving patients in detecting quality gaps in a fragmented healthcare system: development of a questionnaire for Patients' Experiences Across Health Care Sectors (PEACS). Int J Qual Health Care. 2014;26(3):240-249.

31. Ludt, S, Urban E, Eckardt J, et al. Evaluating the quality of colorectal cancer care across the interface of healthcare sectors. PLoS One. 2013; 8(5):e60947.

32. Campbell SM, Braspenning J, Hutchinson A, et al. Research methods used in developing and applying quality indicators in primary care. Qual Saf Health Care. 2002;11(4):358-364. 
33. Black N, Jenkinson C. Measuring patients' experiences and outcomes. BMJ. 2009;339:b2495.

34. Van de Bovenkamp HM, Zuiderent-Jerak T. An empirical study of patient participation in guideline development: exploring the potential for articulating patient knowledge in evidence-based epistemic settings. Health Expect. Epub May 2, 2013.
35. Pohontsch NJ, Herzberg H, Joos S, et al. The professional perspective on patient involvement in the development of quality indicators: a qualitative analysis using the example of chronic heart failure in the German health care setting. Patient Prefer Adherence. 2015;9:151-159.

Patient Preference and Adherence

\section{Publish your work in this journal}

Patient Preference and Adherence is an international, peer-reviewed, open access journal that focuses on the growing importance of patient preference and adherence throughout the therapeutic continuum. Patient satisfaction, acceptability, quality of life, compliance, persistence and their role in developing new therapeutic modalities and compounds to optimize clinical outcomes for existing disease states are major areas of interest for the journal. This journal has been accepted for indexing on PubMed Central. The manuscript management system is completely online and includes a very quick and fair peer-review system, which is all easy to use. Visit http://www. dovepress.com/testimonials.php to read real quotes from published authors.

\footnotetext{
Submit your manuscript here: http://www.dovepress.com/patient-preference-and-adherence-journal
} 